\title{
Robot-assisted versus conventional laparoscopic operation in anus-preserving rectal cancer: a meta-analysis
}

This article was published in the following Dove Press journal:

Therapeutics and Clinical Risk Management

22 September 2017

Number of times this article has been viewed

\author{
Yongzhen Cui ${ }^{1,2, *}$ \\ Cheng $\mathrm{Li}^{3}, *$ \\ Zhongfa $\mathrm{Xu}^{4}$ \\ Yingming Wang ${ }^{1,2}$ \\ Yamei Sun ${ }^{5}$ \\ Huirong $\mathrm{Xu}^{\prime}$ \\ Zengjun $\mathrm{Li}^{\prime}$ \\ Yanlai Sun' \\ 'Department of Gastrointestinal \\ Cancer Surgery, Shandong Cancer \\ Hospital Affiliated to Shandong \\ University, Shandong Academy \\ of Medical Sciences, ${ }^{2}$ School of \\ Medicine and Life Sciences, University \\ of Jinan-Shandong Academy of \\ Medical Sciences, ${ }^{3}$ Department of \\ President's Office, Shandong Cancer \\ Hospital Affiliated to Shandong \\ University, Shandong Academy of \\ Medical Sciences, ${ }^{4}$ Department of \\ Gastrointestinal Surgery, The Affiliated \\ Hospital of Shandong Academy of \\ Medical Sciences, Jinan, ${ }^{5}$ Department \\ of Clinical Laboratory, Zhucheng \\ People's Hospital of Shandong \\ Province, Zhucheng, People's Republic \\ of China
}

*These authors contributed equally to this work
Objective: The aim of this meta-analysis is to provide recommendations for clinical practice and prevention of postoperative complications, such as circumferential resection margin (CRM) involvement, and compare the amount of intraoperative bleeding, safety, operative time, recovery, outcomes, and clinical significance of robot-assisted and conventional laparoscopic procedures in anus-preserving rectal cancer.

Methods: A literature search (PubMed) was performed to identify biomedical research papers and abstracts of studies comparing robot-assisted and conventional laparoscopic procedures. We attempted to obtain the full-text link for papers published between 2000 and 2016, and hand-searched references for relevant literature. RevMan 5.3 software was used for the metaanalysis.

Results: Nine papers (949 patients) were eligible for inclusion; there were 473 patients $(49.8 \%)$ in the robotic group and 476 patients $(50.2 \%)$ in the laparoscopic group. According to the data provided in the literature, seven indicators were used to complete the evaluation. The results of the meta-analysis suggested that robot-assisted procedure was associated with lower intraoperative blood loss (mean difference [MD] -41.15 ; 95\% confidence interval [CI] $-77.51,-4.79$; $P=0.03$ ), lower open conversion rate (risk difference $[\mathrm{RD}]-0.05 ; 95 \% \mathrm{CI}-0.09,-0.01 ; P=0.02$ ), lower hospital stay (MD $-1.07 ; 95 \% \mathrm{CI}-1.80,-0.33 ; P=0.005)$, lower overall complication rate (odds ratio $0.58 ; 95 \% \mathrm{CI} 0.41,0.83 ; P=0.003$ ), and longer operative time (MD 33.73; 95\% CI $8.48,58.99 ; P=0.009)$ compared with conventional laparoscopy. There were no differences in the rate of CRM involvement ( $\mathrm{RD}-0.02 ; 95 \% \mathrm{CI}-0.05,0.01 ; P=0.23$ ) and days to return of bowel function (MD $-0.03 ; 95 \% \mathrm{CI}-0.40,0.34 ; P=0.89$ ).

Conclusion: The Da Vinci robot was superior to laparoscopy with respect to blood loss, open conversion, hospital stay, and postoperative complications during anus-preserving rectal cancer procedures; however, conventional laparoscopy had an advantage regarding operative time. The remaining indicators (CRMs and recovery from intestinal peristalsis) did not differ.

Keywords: rectal cancer, Da Vinci surgical system, laparoscopic surgery, anus-preserving operation, meta-analysis

\section{Introduction}

For a long time, the treatment of low rectal cancer has been a difficult problem. Treatment of low rectal cancer should not only cure the tumor but also retain anal and sexual function and improve the quality of life of patients. With the comprehension of the biological characteristics and anatomic structure of rectal cancer and the maturation of laparoscopic techniques, laparoscopic anus-preserving surgery has been widely carried out for low rectal cancer. To achieve a radical cure in the past, 
distal rectal cancer was resected $\geq 2 \mathrm{~cm}$. Many patients underwent abdominal perineal resection of rectal cancer, but the 5-year survival rate of patients who underwent anal resection and pelvic lymph node dissection did not improve, and in fact, the patients had many complications. ${ }^{1}$ Based on a large clinical pathologic data bank, only $3.6 \%$ of rectal cancer patients have tumors involving the lateral aspect of the intestinal wall invading $>2 \mathrm{~cm}$. Therefore, the tumor resection margin is $<2 \mathrm{~cm}$ or even $1 \mathrm{~cm}$, which is safe. ${ }^{2}$ Kang et $\mathrm{al}^{3}$ conducted a study involving laparoscopic and open surgery of T3N0-2 middle and low rectal cancers and showed that the recovery of the laparoscopic group was better than the open group, and the effect of radical resection was comparable to that of the open surgery. A prospective randomized controlled study confirmed that the safety and efficacy of laparoscopic radical resection of colorectal cancer is equivalent to open surgery. ${ }^{4}$

The Da Vinci robotic surgery system consists of a console, a camera arm, two or three working arms, an operation trolley, and a three-dimensional (3D) video imaging system. The working arm tip of the device can carry out six-dimensional activities. For obese patients with small pelvic and rectal tumors, the operation is more flexible and accurate. Because the Da Vinci robotic surgery system has a greater magnification (10-15 times clear 3D image), it can show better the fine anatomic structure and the choroidal blood vessels of the choroid. Visualization of the loose connective tissue space between the visceral layers of the pelvic fascia is clearer, which ensures complete resection of the mesorectum. ${ }^{5}$ The Da Vinci robotic surgery system can facilitate dissection of the pelvic lymph nodes, ${ }^{6,7}$ and achieve skeletonization of the lymph nodes to protect the pelvic nerves. Sexual and urinary functions are retained, and the quality of life is improved. ${ }^{8,9}$ Radical surgery for rectal cancer is feasible with the Da Vinci robotic surgery system. Anuspreserving surgery for low rectal cancer or ultralow rectal cancer is simple and easy. With this background, our aim was to perform a meta-analysis of the literature to compare the short-term outcomes of robot-assisted and conventional laparoscopic surgery for anus-preserving rectal cancer.

\section{Methods}

\section{Search strategy}

A search of the MEDLINE, Embase, and Ovid databases was performed for studies published before May 2016 comparing clinical or oncologic outcomes of robot-assisted and conventional laparoscopic surgery for anus-preserving rectal cancer.
In addition, the abstracts published at major international conferences were manually searched. The following search terms were used: "anus reserved surgery", "intersphincteric resection", "low anterior resection", "robotic/robotic assisted versus laparoscopic rectal resection", and "robotic/robotic assisted versus laparoscopic low anterior resection".

\section{Study selection and inclusion and exclusion criteria}

The inclusion criteria for this meta-analysis were as follows: 1) randomized and non-randomized studies comparing patients with rectal cancer who underwent anal sphincter-preserving surgery, 2) original literature involving a comparative analysis of the therapeutic effect of robotic and laparoscopic rectal cancer resection, 3) analysis of data integrity with at least one control group of independent research to provide a detailed case count and the number of outcomes under different factors, 4) the research methods of each study were similar and the purpose of the research was consistent, and 5) the results of the study can be represented by corresponding statistical indicators.

According to the quality standard of literature proposed by Lichtenstein et al, ${ }^{10}$ the following were considered unqualified and were excluded: 1) animal experiments; 2) literature reviews, studies with no control group, medical records report, and low-quality literature; 3) studies with sample size <10; and 4) repeated reports of similar content by the same author, reports of too little information, and reports lacking detailed data description in the literature.

\section{Data extraction}

Two researchers obtained full-text articles of relevant studies and independently determined the criteria for inclusion. Disagreements between the two authors were resolved by discussion and consensus. If the negotiation failed, a third independent author was involved. The quality of randomized controlled trials (RCTs) was evaluated using the Cochrane Reviewer's Handbook Jadad scale, ${ }^{11}$ and the quality of the non-randomized controlled trials (NRCTs) was evaluated by the "Methodological Items for Non-Randomized Studies" (Figure 1). ${ }^{12}$ Researchers initially extracted the original data from the literature and converted the data into Excel forms. Missing or incomplete data were obtained by contacting the first author. If there was no response, we acquired the data through a mathematical method, and then discarded the data. Then, we evaluated the primary data integrity to ensure that the data reflected the purpose of this study. 


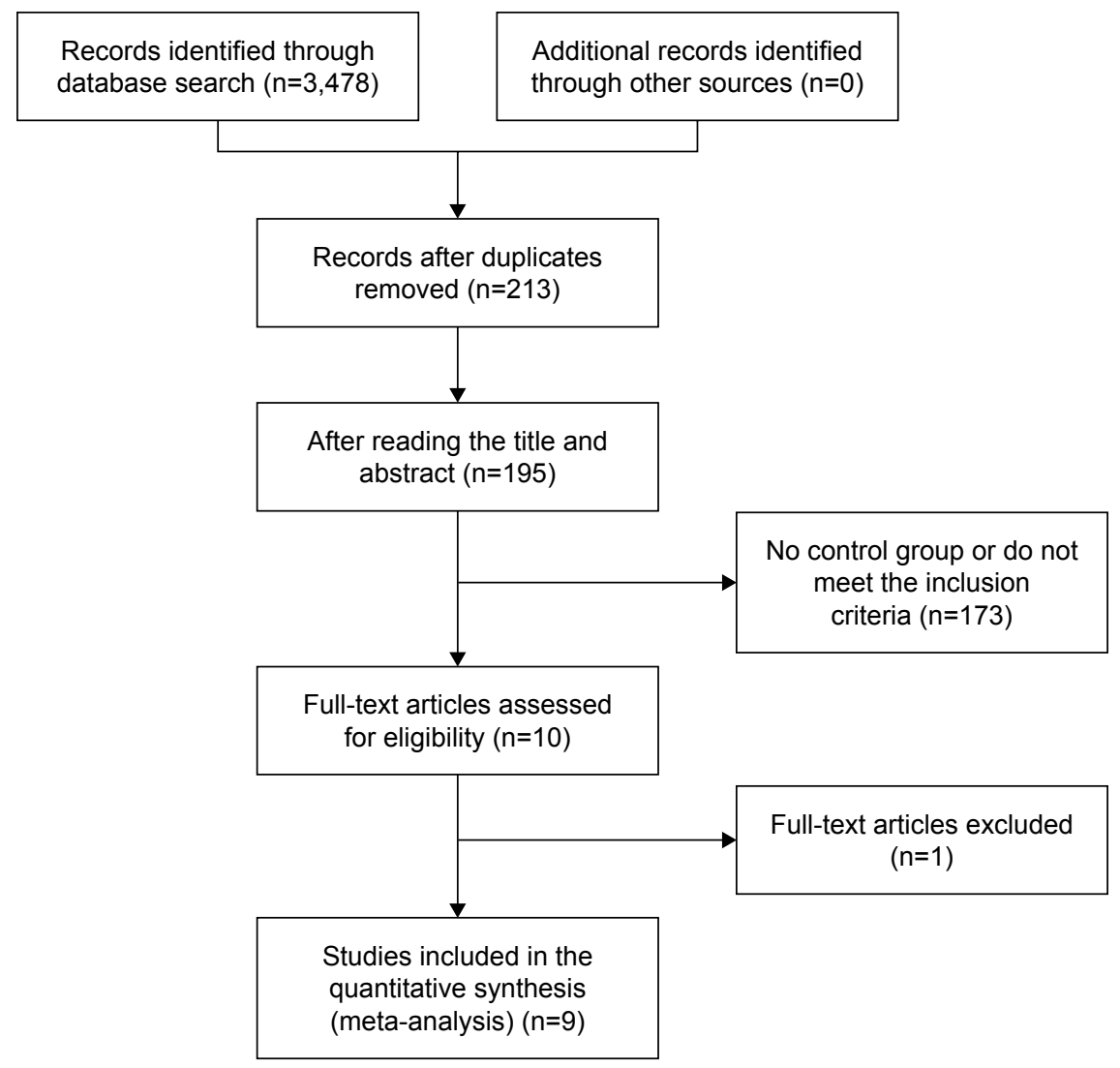

Figure I Flow diagram of study selection for meta-analysis.

The main focus of this meta-analysis was to evaluate the following:

1) intraoperative blood loss $(\mathrm{mL})$

2) rate of circumferential resection margin (CRM) involvement

3) conversion rate

4) days to first passing flatus

5) hospital stay (days)

6) postoperative complications.

\section{Statistical analysis}

Review Manager software (RevMan, version 5.3) provided by the Cochrane Collaboration was used to perform the metaanalysis. Continuous variables were pooled using the mean difference (MD) with a 95\% confidence interval (CI), and dichotomous variables were pooled using the odds ratio (OR) and risk difference (RD) with a 95\% CI. If continuous variables were reported as the median with range, we calculated the means and standard deviations according to Hozo et al. ${ }^{13}$ Statistical heterogeneity was evaluated by $I^{2}$; heterogeneity was considered high if the $I^{2}$ statistic was $>50 \%$. $P<0.05$ was considered statistically significant. The fixed effects model was used for studies with low or moderate statistical heterogeneity, and the random effects model was used for studies with high statistical heterogeneity. Sensitivity analysis was performed by repeating the meta-analysis on the studies that were excluded.

\section{Results Eligible studies}

Using the search terms, we initially retrieved 168 publications. After carefully reviewing the abstracts and full text, we found that nine comparative studies ${ }^{14-22}$ met all the inclusion criteria and were eligible for meta-analysis. The characteristics of patients in the studies included in the meta-analysis are shown in Table 1 . The nine studies involved 949 patients (473 in the robot group and 476 in the laparoscopy group). The nine studies were NRCTs. The anus-preserving operation included a low anterior resection, total mesorectal excision (TME), and intersphincteric resection (ISR). The characteristics of the nine selected studies included in the meta-analysis are listed in Table 2. Of all the studies, two were conducted in Turkey, ${ }^{14,22}$ five in Korea, ${ }^{15,17,18,20,21}$ one in Italy, ${ }^{16}$ and one in the US. ${ }^{19}$ The quality of all the studies was satisfactory. 
Table I Characteristics of patients in studies included in the meta-analysis

\begin{tabular}{|c|c|c|c|c|c|c|c|c|c|c|}
\hline \multirow[t]{2}{*}{ Study } & \multirow[t]{2}{*}{ Country } & \multirow{2}{*}{$\begin{array}{l}\text { Robotic and } \\
\text { laparoscopic } \\
\text { mean BMI }\end{array}$} & \multirow[t]{2}{*}{$\begin{array}{l}\text { Sex } \\
(M: F)\end{array}$} & \multicolumn{3}{|c|}{$\begin{array}{l}\text { Tumor location } \\
\text { from anal verge }(n)\end{array}$} & \multirow[t]{2}{*}{$\begin{array}{l}\text { Previous } \\
\text { surgery (\%) }\end{array}$} & \multirow[t]{2}{*}{$\begin{array}{l}\text { Pre-op } \\
\text { CRT (\%) }\end{array}$} & \multirow[t]{2}{*}{$\begin{array}{l}\text { Ileostomy } \\
\text { (\%) }\end{array}$} & \multirow[t]{2}{*}{$\begin{array}{l}\text { Leak } \\
\text { rate (\%) }\end{array}$} \\
\hline & & & & Upper & Middle & Lower & & & & \\
\hline \multirow[t]{2}{*}{ Erguner et $\mathrm{al}^{14}$} & Turkey & R-LAR: 28.3 & $14: 13$ & 8 & 16 & 3 & - & $4(14.8 I)$ & - & - \\
\hline & & L-LAR: 26.8 & $20: 17$ & 20 & 13 & 4 & - & $8(21.62)$ & - & 3 \\
\hline \multirow[t]{2}{*}{ Baek et al ${ }^{15}$} & South Korea & R-LAR: 23.4 & $31: 16$ & - & - & - & - & - & - & $4(8.5)$ \\
\hline & & L-LAR: 23.4 & $28: 9$ & - & - & - & - & - & - & $3(8.1)$ \\
\hline \multirow[t]{2}{*}{$D^{\prime}$ Annibale et al ${ }^{16}$} & Italy & - & $30: 20$ & 8 & 9 & 33 & - & 34 & - & $5(10)$ \\
\hline & & - & $30: 20$ & 21 & 12 & 17 & - & 28 & - & $7(14)$ \\
\hline \multirow[t]{2}{*}{ Baik et $\mathrm{al}^{17}$} & South Korea & R-LAR: 23.4 & $37: 19$ & - & - & - & I (I.8) & $5(8.9)$ & - & 1 \\
\hline & & L-LAR: 23.2 & $34: 23$ & - & - & - & $5(8.8)$ & $7(12.3)$ & - & 4 \\
\hline \multirow[t]{2}{*}{ Park et al ${ }^{18}$} & South Korea & R-LAR: 23.1 & $86: 47$ & 40 & 60 & 33 & $10(7.5)$ & $15(11.3)$ & $29(21.8)$ & 6 \\
\hline & & L-LAR: 22.9 & $60: 24$ & 31 & 37 & 16 & $11(13.1)$ & $10(11.9)$ & $20(23.8)$ & 3 \\
\hline \multirow[t]{2}{*}{ Pigazzi et al ${ }^{19}$} & US & R-TME: 31.0 & $2: 4$ & - & - & - & 2 & 2 & - & - \\
\hline & & L-TME: 27.0 & $4: 2$ & - & - & - & 3 & 2 & - & - \\
\hline \multirow[t]{2}{*}{ Park et $\mathrm{a}^{20}$} & South Korea & R-ISR: 23.9 & $28: 12$ & - & - & - & $4(10.0)$ & $32(80.0)$ & $14(35.0)$ & 3 \\
\hline & & L-ISR: 24.3 & $25: 15$ & - & - & - & $8(20.0)$ & $20(50.0)$ & $6(14.3)$ & 2 \\
\hline \multirow[t]{2}{*}{ Kim and Kang ${ }^{2 l}$} & South Korea & R-TME: 23.6 & $70: 30$ & 19 & 49 & 32 & 7 & $14(14.0)$ & $30(30.0)$ & $8(8.2)$ \\
\hline & & L-TME: 23.5 & $57: 43$ & 17 & 64 & 19 & 10 & $7(7.0)$ & $27(27.0)$ & II (II.I) \\
\hline \multirow[t]{2}{*}{ Serin et $\mathrm{al}^{22}$} & Turkey & R-TME: 24.7 & $14: 0$ & - & - & - & - & 14 & - & 1 \\
\hline & & L-TME: 26.0 & $65: 0$ & - & - & - & - & 65 & - & 6 \\
\hline
\end{tabular}

Abbreviations: BMI, body mass index; CRT, chemoradiation therapy; LAR, low anterior resection; TME, total mesorectal excision; ISR, intersphincteric resection.

The robot group had longer operative times, lower intraoperative blood loss, shorter hospital stays, lower overall postoperative complications, and a lower open conversion rate; however, there was no difference in the rate of CRM involvement and days to return of bowel function.

\section{Blood loss}

Five studies ${ }^{14,15,18-20}$ reported the intraoperative blood loss. There was significant heterogeneity in the data in the literature $\left(I^{2}=84 \%\right)$ and no evidence of publication bias (Figure 2). Thus, the random effects model was used, and the MD was determined. The meta-analysis (Figure 3) showed that the robot group had a lower intraoperative blood loss (MD $-41.15 ; 95 \% \mathrm{CI}-77.51,-4.79 ; P=0.03$ ) compared with the laparoscopy group.

\section{CRM involvement}

Six studies ${ }^{15-18,20,21}$ reported the CRM involvement. There was no significant heterogeneity in the data in the literature $\left(I^{2}=34 \%\right)$ or publication bias (Figure 4$)$. The fixed effect model was used, and the $\mathrm{RD}$ was determined. The meta-analysis (Figure 5) showed that the result was considered not statistically significant (RD $-0.02 ; 95 \% \mathrm{CI}-0.05,0.01 ; P=0.23$ ).

\section{Conversion rate}

Eight studies ${ }^{14-18,20-22}$ reported the conversion rate. There was significant heterogeneity in the data in the literature $\left(I^{2}=63 \%\right)$, but no evidence of publication bias (Figure 6). Thus, the random effects model was used, and the RD was determined. The meta-analysis (Figure 7) showed that the result was statistically significant $(\mathrm{RD}-0.05 ; 95 \% \mathrm{CI}-0.09,-0.01 ; P=0.02)$.

Table 2 Characteristics of the nine selected studies included in the meta-analysis

\begin{tabular}{|c|c|c|c|c|c|c|c|c|c|c|}
\hline \multirow[t]{2}{*}{ Study } & \multirow[t]{2}{*}{ Year } & \multirow[t]{2}{*}{ Country } & \multicolumn{3}{|c|}{ Study size (n) } & \multirow[t]{2}{*}{ TME } & \multirow[t]{2}{*}{ Objective } & \multirow[t]{2}{*}{ Randomized } & \multirow[t]{2}{*}{ Follow-up } & \multirow[t]{2}{*}{ Intervention } \\
\hline & & & Total & R-LAR & L-LAR & & & & & \\
\hline Baik et al ${ }^{17}$ & 2009 & South Korea & 113 & 56 & 57 & Yes & Yes & No & Yes & No \\
\hline Baek et al ${ }^{15}$ & 2013 & South Korea & 84 & 47 & 37 & No & Yes & No & Yes & No \\
\hline$D^{\prime} A n n i b a l e ~ e t ~ a l^{16}$ & 2013 & Italy & 100 & 50 & 50 & Yes & Yes & No & Yes & No \\
\hline Erguner et al ${ }^{14}$ & 2013 & Turkey & 64 & 27 & 37 & No & Yes & No & Yes & No \\
\hline Park et $\mathrm{al}^{18}$ & 2015 & South Korea & 217 & 133 & 84 & Yes & Yes & No & Yes & No \\
\hline Pigazzi et al ${ }^{19}$ & 2006 & US & 12 & 6 & 6 & Yes & Yes & No & Yes & No \\
\hline Park et $\mathrm{al}^{20}$ & 2013 & South Korea & 80 & 40 & 40 & No & Yes & No & Yes & No \\
\hline Kim and Kang ${ }^{21}$ & 2010 & South Korea & 200 & 100 & 100 & Yes & Yes & No & Yes & No \\
\hline Serin et $\mathrm{a}^{22}$ & 2015 & Turkey & 79 & 14 & 65 & Yes & Yes & No & No & No \\
\hline
\end{tabular}

Abbreviations: TME, total mesorectal excision; LAR, low anterior resection. 


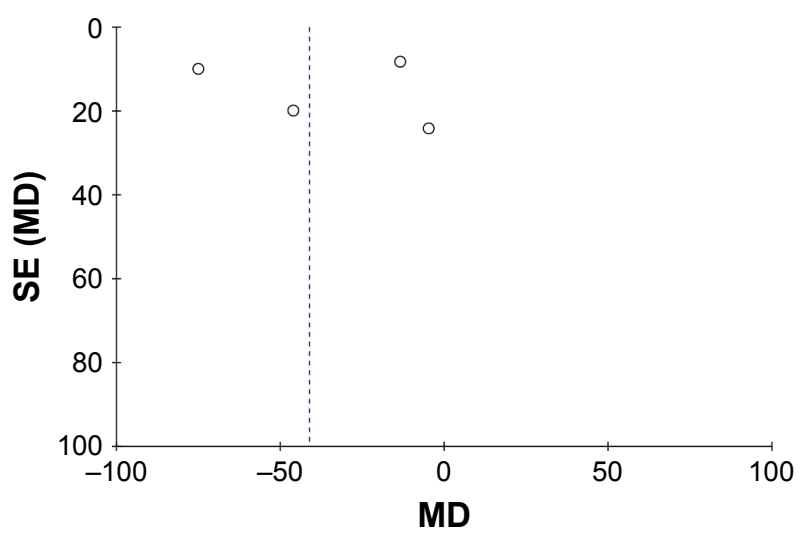

Figure 2 Funnel plot of blood loss outcome. Abbreviations: SE, standard error; MD, mean difference.

\section{Days to first passing flatus}

Six studies ${ }^{15,17,18,20-22}$ reported the days to first passing flatus. There was significant heterogeneity in the data in the literature $\left(I^{2}=73 \%\right)$ and no evidence of publication bias. Thus, the random effects model was used, and the MD was determined. The results of the meta-analysis (Figure 8) showed that the result was not statistically significant (MD $-0.03 ; 95 \%$ CI $-0.40,0.34, P=0.89$ ).

\section{Hospital stay}

Eight studies ${ }^{14,15,17-22}$ reported the length of hospital stay. There was significant heterogeneity in the data in the literature $\left(I^{2}=75 \%\right)$ and no evidence of publication bias. Thus, the random effects model was used, and the MD was performed. The result of the meta-analysis (Figure 9) showed that the result was statistically significant (MD $-1.07 ; 95 \%$ CI $-1.80,-0.33 ; P=0.005$ ).

\section{Operative time}

Nine studies ${ }^{14-22}$ reported the operative time. There was significant heterogeneity in the data in the literature $\left(I^{2}=96 \%\right)$ and no evidence of publication bias. Thus, the random effects model was used, and the MD was performed. The results of the meta-analysis (Figure 10) showed that the result was statistically significant (MD 33.73; 95\% CI 8.48, 58.99; $P=0.009$ ).

\section{Postoperative complications}

Nine studies ${ }^{14-22}$ reported the postoperative complications. There was no significant heterogeneity in the data in the literature $\left(I^{2}=0 \%\right)$ or evidence of publication bias. Thus, the fixed effects model was used, and the OR was determined. The results of the meta-analysis (Figure 11) showed that the

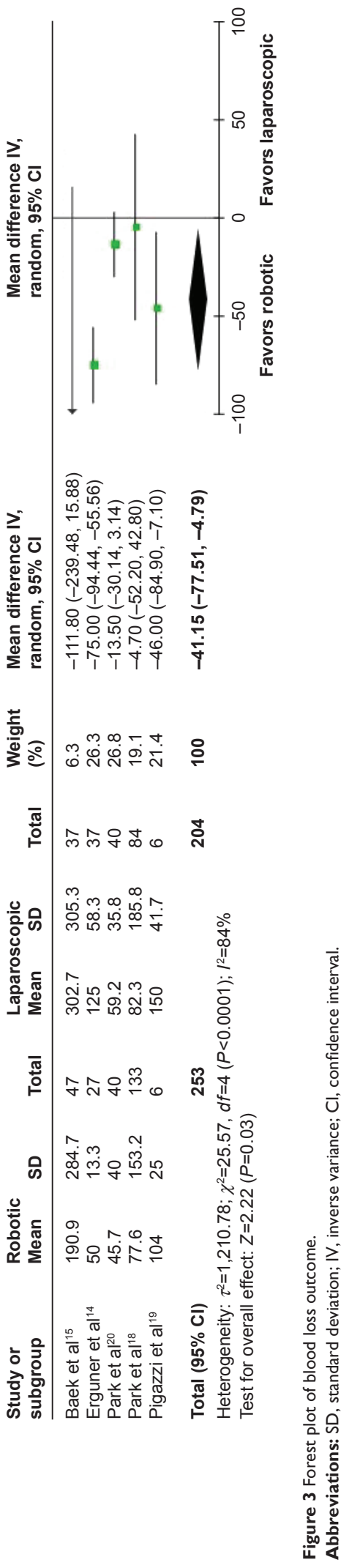




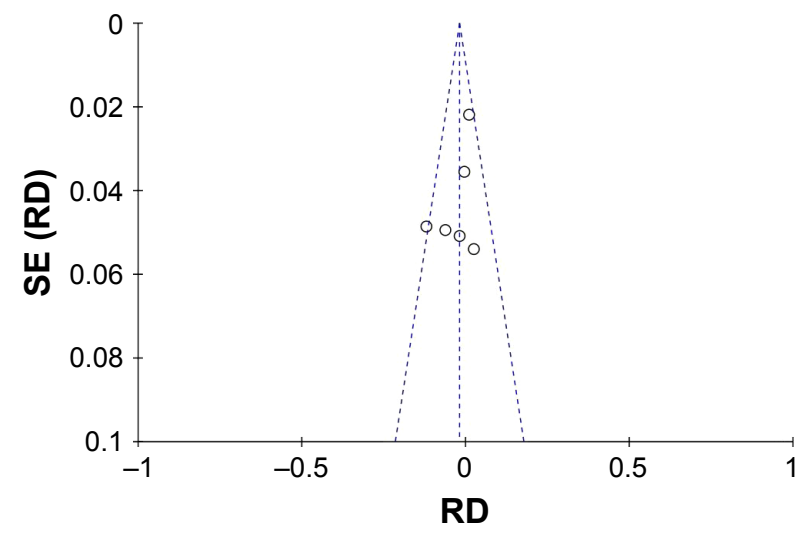

Figure 4 Funnel plot of involvement of circumferential resection margin outcome. Abbreviations: SE, standard error; RD, risk difference.

result was statistically significant (OR 0.58; 95\% CI 0.41 , $0.83 ; P=0.003)$.

\section{Publication bias estimate}

We used funnel plots to evaluate all of the possible publication biases that were included in the literature.

\section{Discussion}

Currently, the clinical application of robotic surgery system for colorectal cancer resection is still in the exploratory stage. Indeed, it is more difficult to implement RCTs in the surgical field. Therefore, the current meta-analysis is mainly based on NRCTs. After analyzing the basic patient data, we found that the two groups had more male patients than females. In addition, the age of the patients in the robot group was small. The Da Vinci robotic surgery system is still in the exploratory stage, ${ }^{23}$ which may have caused the selection bias in this finding. The above two reasons also support the conclusion of our study; specifically, the robotic group had a shorter hospital stay and a lower incidence of short-term complications. The surgical approaches in studies included in this meta-analysis were total mesorectal excision ${ }^{14-19,21,22}$ and $\mathrm{ISR}^{20}$ for resection of rectal cancer. Erguner et al ${ }^{14}$ included partial mesorectal excision and TME in their study.

The results of this study showed that the amount of bleeding in the robotic group was significantly less than the laparoscopic group $(P<0.05)$. The field of vision in Da Vinci surgical system is more open; thus, it is possible to visualize the microscopic blood vessels and nerves that are not easily visualized during laparoscopic surgery. ${ }^{24}$ At the same time, operation with a robotic surgery system is flexible and free from tremor, which ensures the stability and accuracy of the operation. ${ }^{25,26}$ The Da Vinci surgical system allows visualization of the blood vessels around the fat and proper lymph

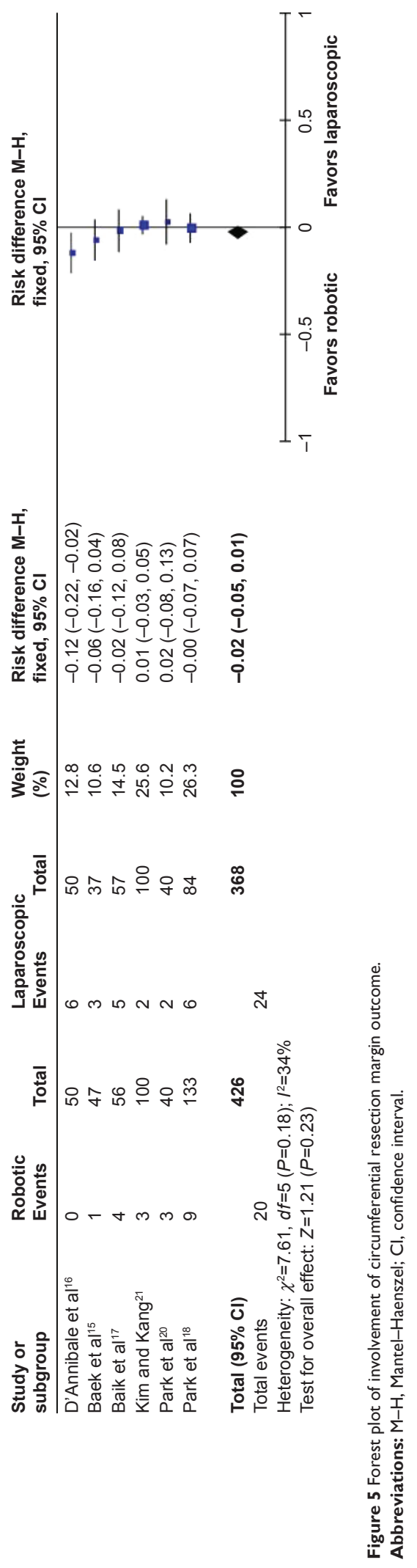




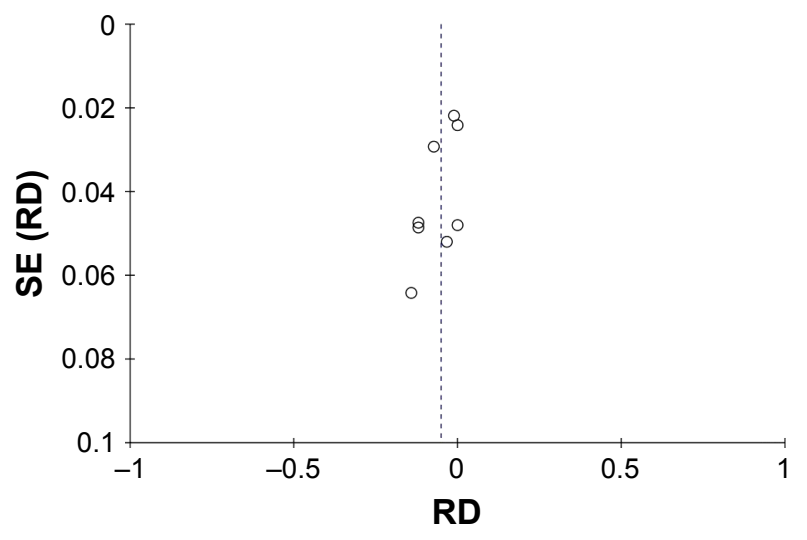

Figure 6 Funnel plot of conversion rate outcome. Abbreviations: SE, standard error; RD, risk difference.

node dissection, and the blood vessels and nerves cannot be easily damaged, resulting in higher security.

Involvement of CRM is defined as when the tumor is located $\leq 1 \mathrm{~mm}$ from the CRM. ${ }^{27}$ A safe CRM can be achieved with the robotic system compared with the conventional laparoscopy. ${ }^{28}$ However, the results of our study were not statistically different between the groups. Moreover, the CLASICC trial ${ }^{29}$ also showed the same results. Park et al ${ }^{18}$ proposed that the rate of CRM involvement is mainly influenced by two factors: the location of the tumor in the rectum and the quality of the surgery. Because the location of the tumor is random and a key factor is the quality of dissection, robotic surgery is more dominant in the macroscopic grading than conventional laparoscopic surgery. In the future, a large number of RCTs are needed for further validation.

We found no differences between the robot and laparoscopy groups in the time to first passing flatus. Rational evaluation of intestinal function and recovery of diet played a key role in shortening the length of hospital stay.

The current study showed noteworthy differences between the groups in the rate of conversion to open surgery. The laparoscopy group had a higher rate of conversion to open surgery than the robot group. A number of studies have indicated that laparoscopic surgery was difficult to perform in narrow spaces and the deep space of the cavum pelvis. Therefore, the surgeon is required to have fairly high experience and learning curve. ${ }^{30-37}$ Another important issue is that laparoscopic techniques have low dexterity and does not allow flexible bending. Moreover, two-dimensional vision and the camera field of vision heavily depend on the ability of the assistant. ${ }^{38,39}$ The Da Vinci surgical system appears to overcome many disadvantages of laparoscopic surgery, ensuring good operational flexibility, 3D visual field, and filtering of physiological shock. ${ }^{40}$

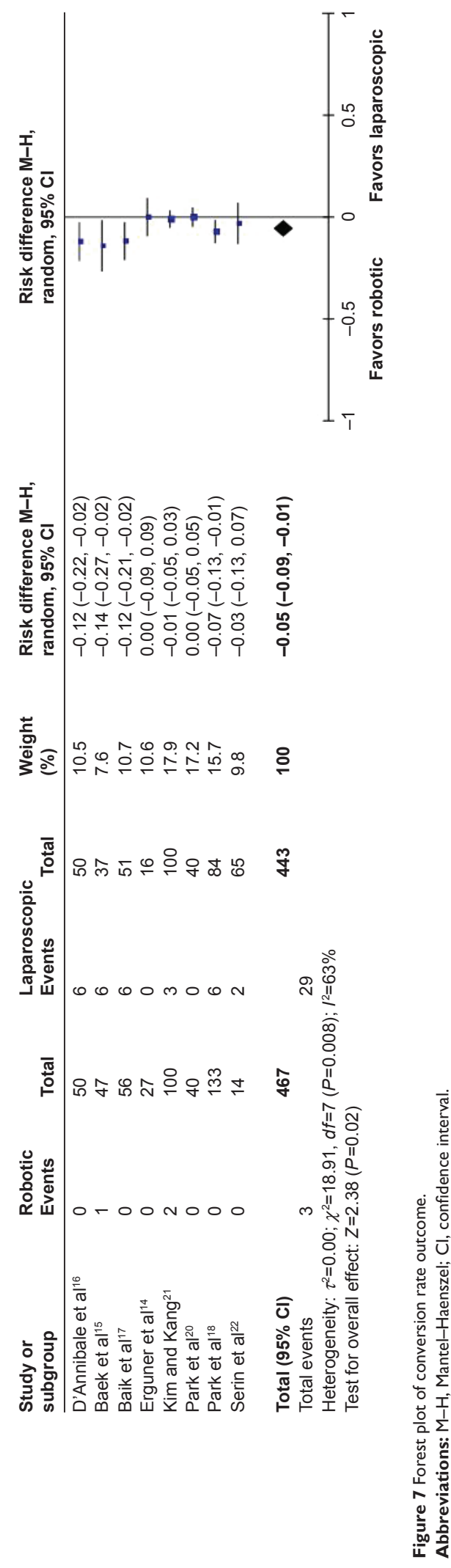



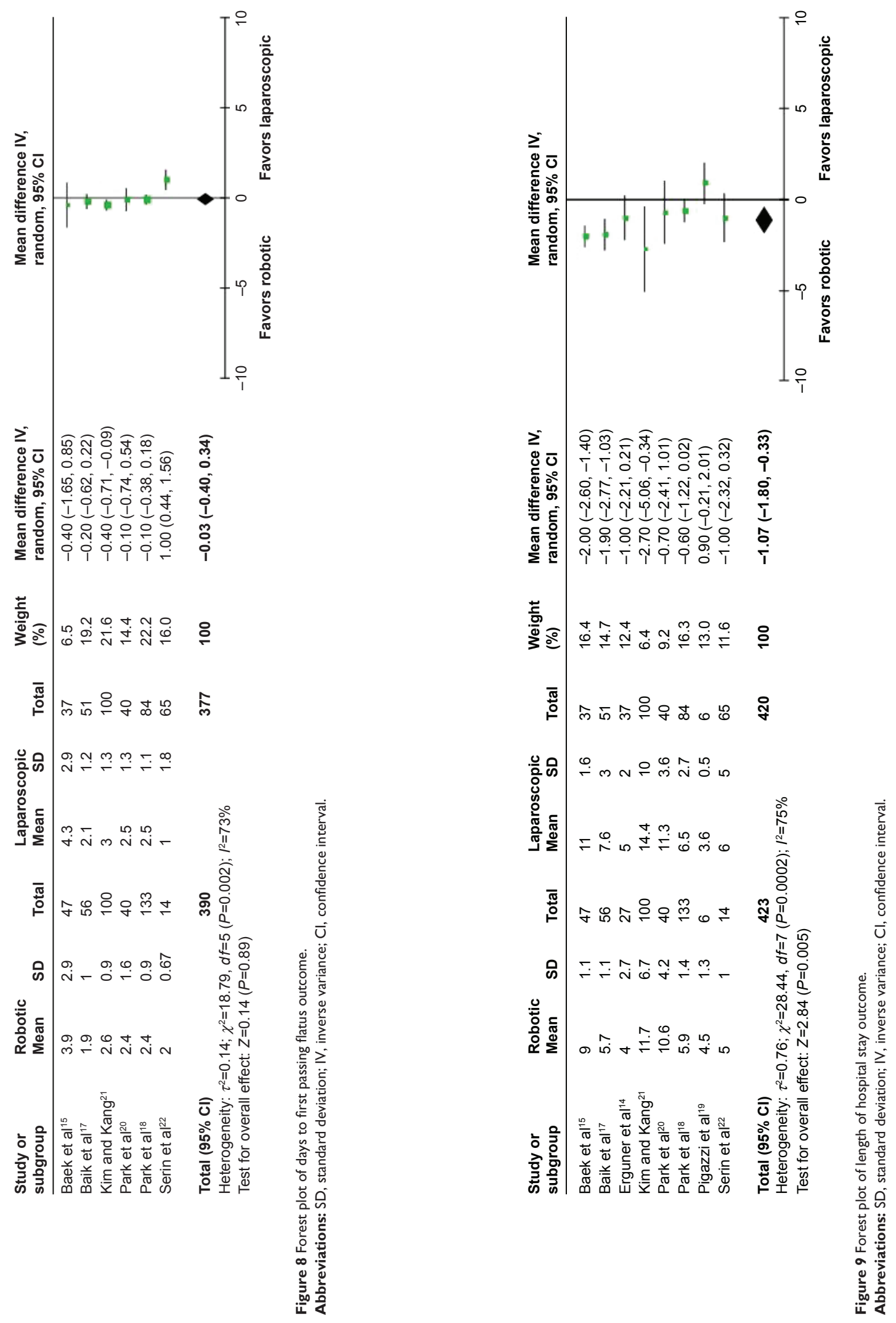

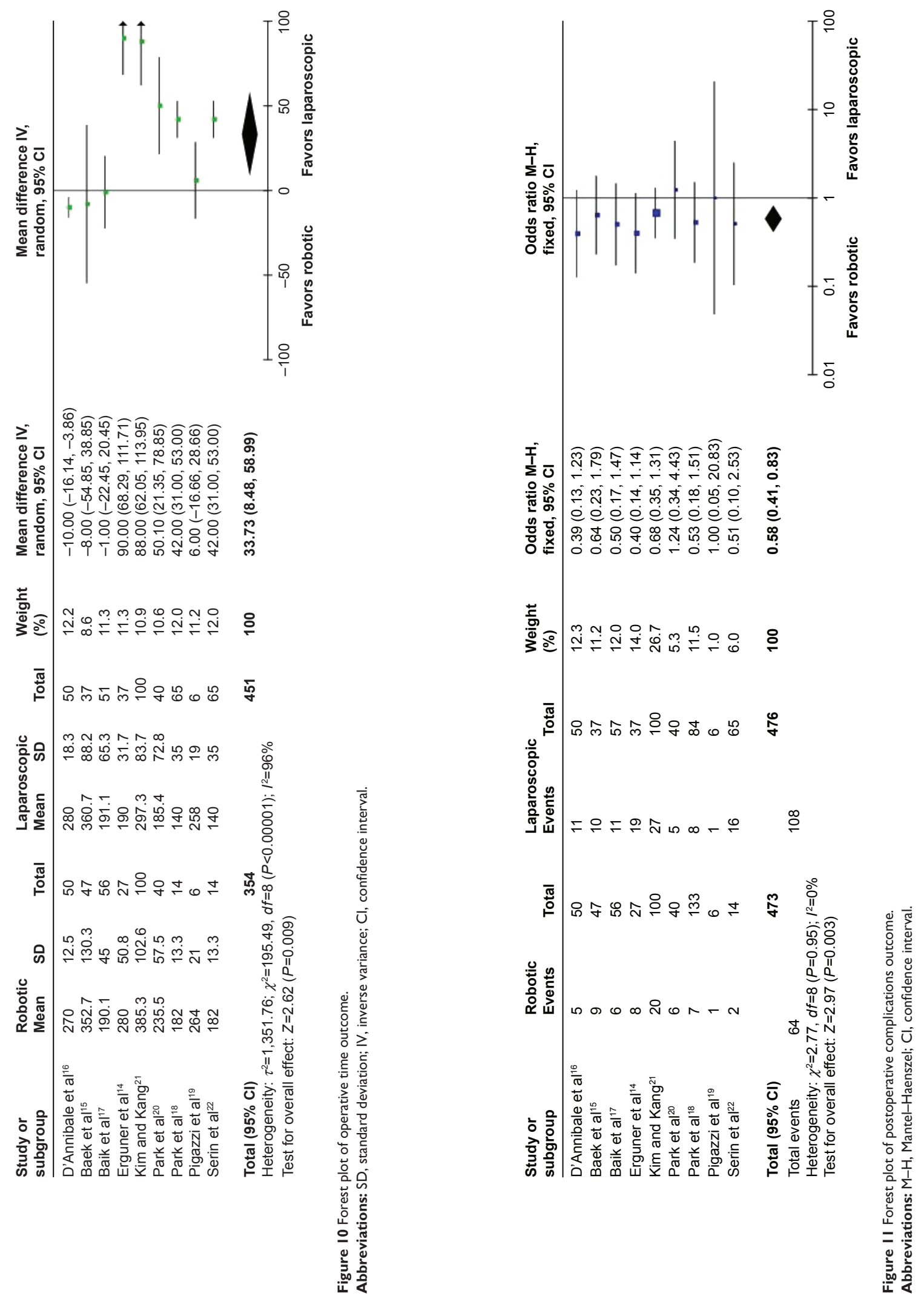
Our results showed that compared with the robot group, the laparoscopy group had shorter surgical operative times. This finding may be associated with the initial operation of the Da Vinci system, which requires adjusting the position of the machine, in addition to the following: fixing the operating arm in position is time-consuming, there is lack of experience in trocar placement, the inexperienced physicians and nurses are not helpful, and the replacement of surgical instruments is time-consuming. ${ }^{41}$ After gaining experience with various surgeries, the operation of the Da Vinci surgery system can offer the advantage of flexibility, and the operation time can also be shortened.

The biggest shortcoming with the robotic surgery system is its high cost because the acquisition and maintenance costs are higher. Due to the cost, the two groups are less frequently compared in the literature. Thus, in this study, the cost was not compared. A recent meta-analysis also showed that the cost of robotic surgery is much higher than laparoscopic surgery, and patient benefit is not apparent. ${ }^{42}$

\section{Study limitations}

This meta-analysis has the following limitations: 1) Because of the difference in the cost of the two types of operative methods and the medical, moral, and ethical issues, it is difficult to achieve randomization and blinding. This paper mainly included non-randomized controlled studies and had selection, performance, and measurement bias. 2) The number of patients included in the literature and the number of studies were relatively small; thus, we could not carry out subgroup and sensitivity analysis. The conclusion was the credibility of the reduction. 3) The presence of confounding factors in the literature may not be resolved, resulting in bias. 4) We could not eliminate the differences in patients, and the skills and experience of surgeons between the two groups. The present study compared the short-term effect, which is not sufficient; there was no long-term curative effect to compare postoperatively. We look forward to future research and multicenter RCTs to verify our findings and provide strong evidence for clinical diagnosis and treatment.

In conclusion, compared with laparoscopic rectal cancer surgery, the robotic surgery is advantageous. Although the robotic operation requires more time, the intraoperative blood loss is less and the postoperative complication rate is low. However, in addition to being more expensive, robotic surgery has a steeper learning curve, with similar complication rates and oncologic surrogate markers of successful surgery. Therefore, further improving the medical technology level, reducing costs and improving the surgeon's proficiency, can increase the advantage of robotic surgery significantly.

\section{Acknowledgments}

This work was supported by grants from medical and health technology development program foundation of Shandong Province (no 2015WS0149 and no 2015WS0197), science and technology development plan of Jinan (no 201401253), and science and technology foundation of Shandong Academy of Medical Sciences (no 2013-45 and no 2014-04).

\section{Author contributions}

YL Sun and ZF Xu designed the research. YL Sun, ZF Xu, and YZ Cui performed the research. C Li, ZJ Li, and YM Wang analyzed the data. YL Sun, YZ Cui, and C Li wrote the paper. All authors contributed toward data analysis, drafting and critically revising the paper and agree to be accountable for all aspects of the work.

\section{Disclosure}

The authors report no conflicts of interest in this work.

\section{References}

1. Fujita S, Akasu T, Mizusawa J, et al; Colorectal Cancer Study Group of Japan Clinical Oncology Group. Postoperative morbidity and mortality after mesorectal excision with and without lateral lymph node dissection for clinical stage II or stage III lower rectal cancer (JCOG0212): results from a multicentre, randomised controlled, non-inferiority trial. Lancet Oncol. 2012;13(6):616-621.

2. Nelson H, Petrelli N, Carlin A, et al; National Cancer Institute Expert Panel. Guidelines 2000 for colon and rectal cancer surgery. $J$ Natl Cancer Inst. 2001;93(8):583-596.

3. Kang SB, Park JW, Jeong SY, et al. Open versus laparoscopic surgery for mid or low rectal cancer after neoadjuvant chemoradiotherapy (COREAN trial): short-term outcomes of an open-label randomised controlled trial. Lancet Oncol. 2010;11(7):637-645.

4. deSouza AL, Prasad LM, Ricci J, et al. A comparison of open and robotic total mesorectal excision for rectal adenocarcinoma. Dis Colon Rectum. 2011;54(3):275-282.

5. Zimmern A, Prasad L, Desouza A, Marecik S, Park J, Abcarian H. Robotic colon and rectal surgery: a series of 131 cases. World J Surg. 2010;34(8):1954-1958.

6. Ziogas D, Roukos D. Robotic surgery for rectal cancer: may it improve also survival? Surg Endosc. 2008;22:1405-1406.

7. Kim JC, Yang SS, Jang TY, Kwak JY, Yun MJ, Lim SB. Open versus robot-assisted sphincter-saving operations in rectal cancer patients: techniques and comparison of outcomes between groups of 100 matched patients. Int J Med Robot. 2012;8(4):468-475.

8. Broholm M, Pommergaard HC, Gögenür I. Possible benefits of robotassisted rectal cancer surgery regarding urological and sexual dysfunction: a systematic review and meta-analysis. Colorectal Dis. 2015;17(5): 375-381.

9. Luca F, Valvo M, Ghezzi TL, et al. Impact of robotic surgery on sexual and urinary functions after fully robotic nerve-sparing total mesorectal excision for rectal cancer. Ann Surg. 2013;257(4):672-678.

10. Lichtenstein MJ, Mulmw CD, Elwood PC. Guidelines for reading case-control studies. J Chronic Dis. 1987;40(9):893-903. 
11. Clark HD, Wells GA, Huët C, et al. Assessing the quality of randomized trials: reliability of the Jadad scale. Control Clin Trials. 1999;20(5): 448-452.

12. Slim K, Nini E, Forestier D, Kwiatkowski F, Panis Y, Chipponi J. Methodological index for non-randomized studies (MINORS): development and validation of a new instrument. ANZ J Surg. 2003;73(9): $712-716$.

13. Hozo SP, Djulbegovic B, Hozo I. Estimating the mean and variance from the median, range, and the size of a sample. BMC Med Res Methodol. 2005;5:13.

14. Erguner I, Aytac E, Boler DE, et al. What have we gained by performing robotic rectal resection? Evaluation of 64 consecutive patients who underwent laparoscopic or robotic low anterior resection for rectal adenocarcinoma. Surg Laparosc Endosc Percutan Tech. 2013;23(3): 316-319.

15. Baek SJ, Al-Asari S, Jeong DH, et al. Robotic versus laparoscopic coloanal anastomosis with or without intersphincteric resection for rectal cancer. Surg Endosc. 2013;27(11):4157-4163.

16. D’Annibale A, Pernazza G, Monsellato I, et al. Total mesorectal excision: a comparison of oncological and functional outcomes between robotic and laparoscopic surgery for rectal cancer. Surg Endosc. 2013;27(6):1887-1895.

17. Baik SH, Kwon HY, Kim JS, et al. Robotic versus laparoscopic low anterior resection of rectal cancer: short-term outcome of a prospective comparative study. Ann Surg Oncol. 2009;16(6):1480-1487.

18. Park EJ, Cho MS, Baek SJ, et al. Long-term oncologic outcomes of robotic low anterior resection for rectal cancer: a comparative study with laparoscopic surgery. Ann Surg. 2015;261(1):129-137.

19. Pigazzi A, Ellenhorn JD, Ballantyne GH, Paz IB. Robotic-assisted laparoscopic low anterior resection with total mesorectal excision for rectal cancer. Surg Endosc. 2006;20(10):1521-1525.

20. Park SY, Choi GS, Park JS, Kim HJ, Ryuk JP. Short-term clinical outcome of robot-assisted intersphincteric resection for low rectal cancer: a retrospective comparison with conventional laparoscopy. Surg Endosc. 2013;27(1):48-55.

21. Kim NK, Kang J. Optimal total mesorectal excision for rectal cancer: the role of robotic surgery from an expert's view. J Korean Soc Coloproctololgy. 2010;26(6):377-387.

22. Serin KR, Gultekin FA, Batman B, et al. Robotic versus laparoscopic surgery for mid or low rectal cancer in male patients after neoadjuvant chemoradiation therapy: comparison of short-term outcomes. J Robotic Surg. 2015;9(3):187-194.

23. Baik SH, Kang CM, Lee WJ, et al. Robotic total mesorectal excision for the treatment of rectal cancer. J Robot Surg. 2007;1(1):99-102.

24. Najarian S, Fallahnezhad M, Afshari E. Advances in medical robotic systems with specific applications in surgery-a review. J Med Eng Technol. 2011;35(1):19-33.

25. Ruurda JP, Broeders IA, Pulles B, Kappelhof FM, van der Werken C. Manual robot assisted endoscopic suturing: time-action analysis in an experimental model. Surg Endosc. 2004;18(8):1249-1252.

26. Arora A, Cunningham A, Chawdhary G, et al. Clinical applications of telerobotic ENT-head and neck surgery. Int J Surg. 2011;9(4): 277-284.

27. Adam IJ, Mohamdee MO, Martin IG, et al. Role of circumferential margin involvement in the local recurrence of rectal cancer. Lancet. 1994;344(8924):707-711.
28. Leonard D, Penninckx F, Fieuws S, et al; PROCARE, a multidisciplinary Belgian Project on Cancer of the Rectum. Factors predicting the quality of total mesorectal excision for rectal cancer. Ann Surg. 2010;252(6): 982-988.

29. Jayne DG, Thorpe HC, Copeland J, Quirke P, Brown JM, Guillou PJ. Five-year follow-up of the Medical Research Council CLASICC trial of laparoscopically assisted versus open surgery for colorectal cancer. Br J Surg. 2010;97(11):1638-1645.

30. Ito M, Sugito M, Kobayashi A, Nishizawa Y, Tsunoda Y, Saito N. Influence of learning curve on short-term results after laparoscopic resection for rectal cancer. Surg Endosc. 2009;23(2):403-408.

31. Schlachta CM, Mamazza J, Seshadri PA, Cadeddu M, Gregoire R, Poulin EC. Defining a learning curve for laparoscopic colorectal resections. Dis Colon Rectum. 2001;44(2):217-222.

32. Li GX, Yan HT, Yu J, Lei ST, Xue Q, Cheng X. [Learning curve of laparoscopic resection for rectal cancer]. Nan Fang Yi Ke Da Xue Xue Bao. 2006;26(4):535-538. Chinese [with English abstract].

33. Iversen LH, Harling H, Laurberg S, Wille-Jørgensen P. Influence of caseload and surgical speciality on outcome following surgery for colorectal cancer: a review of evidence. Part 1: short-term outcome. Colorectal Dis. 2007;9(1):28-37.

34. Balik E, Asoglu O, Saglam S, et al. Effects of surgical laparoscopic experience on the short-term postoperative outcome of rectal cancer: results of a high volume single center institution. Surg Laparosc Endosc Percutan Tech. 2010;20(2):93-99.

35. Agha A, Fürst A, Iesalnieks I, et al. Conversion rate in 300 laparoscopic rectal resections and its influence on morbidity and oncological outcome. Int J Colorectal Dis. 2008;23(4):409-417.

36. Bege T, Lelong B, Esterni B, et al. The learning curve for the laparoscopic approach to conservative mesorectal excision for rectal cancer: lessons drawn from a single institution's experience. Ann Surg. 2010;251(2):249-253.

37. Park IJ, Choi GS, Lim KH, Kang BM, Jun SH. Multidimensional analysis of the learning curve for laparoscopic colorectal surgery: lessons from 1,000 cases of laparoscopic colorectal surgery. Surg Endosc. 2009;23(4):839-846.

38. Cadiere GB, Himpens J, Germay O, et al. Feasibility of robotic laparoscopic surgery: 146 cases. World J Surg. 2001;25(11):1467-1477.

39. Berguer R, Rab GT, Abu-Ghaida H, Alarcon A, Chung J. A comparison of surgeons' posture during laparoscopic and open surgical procedures. Surg Endosc. 1997;11(2):139-142.

40. Lanfranco AR, Castellanos AE, Desai JP, Meyers WC. Robotic surgery: a current perspective. Ann Surg. 2004;239(1):14-21.

41. Jiménez Rodríguez RM, Díaz Pavón JM, de La Portilla de Juan F, Prendes Sillero E, Hisnard Cadet Dussort JM, Padillo J. [Prospective randomised study: robotic-assisted versus conventional laparoscopic surgery in colorectal cancer resection]. Cir Esp. 2011;89(7):432-438. Spanish [with English abstract].

42. Keller DS, Senagore AJ, Lawrence JK, Champagne BJ, Delaney CP Comparative effectiveness of laparoscopic versus robot-assisted colorectal resection. Surg Endosc. 2014;28(1):212-221.
Therapeutics and Clinical Risk Management

\section{Publish your work in this journal}

Therapeutics and Clinical Risk Management is an international, peerreviewed journal of clinical therapeutics and risk management, focusing on concise rapid reporting of clinical studies in all therapeutic areas outcomes, safety, and programs for the effective, safe, and sustained use of medicines. This journal is indexed on PubMed Central, CAS,

\section{Dovepress}

EMBase, Scopus and the Elsevier Bibliographic databases. The manuscript management system is completely online and includes a very quick and fair peer-review system, which is all easy to use. Visit http://www.dovepress.com/testimonials.php to read real quotes from published authors. 